\title{
O DODECASSÍLABO IÂMBICO MISTO: UMA PROPOSTA PARA A ADAPTAÇÃO DO VERSO BRANCO ÉPICO INGLÊS AO PORTUGUÊS
}

\author{
THE MIXED IAMBIC DODECASYLLABLE: A PROPOSAL FOR THE \\ ADAPTATION OF THE ENGLISH EPIC BLANK VERSE INTO PORTUGUESE
}

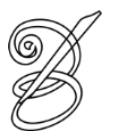 \\ Angiuli Copetti de AGUIAR* \\ Universidade Federal de Santa Maria, Brasil
}

\begin{abstract}
Resumo: A tradução do verso branco épico usualmente toma duas formas: fidelidade formal à contagem silábica como recriação do pentâmetro em decassílabos ou fidelidade semântica como transposição adaptativa em versos livres. Ambos os modos causam detrimento aos efeitos particulares da forma original por não transporem à língua de chegada as qualidades essenciais do verso branco inglês: o ritmo cadenciado e constante e a tensão entre o ritmo métrico e o ritmo sintático-semântico. Em nosso artigo, buscamos estudar as qualidades e efeitos que tornam o verso branco épico distinto de outras formas métricas, explorando os mecanismos do pentâmetro iâmbico, seus limites e mutações dentro da tradição inglesa, e como esse verso opera em composições não-rimadas de caráter narrativo e meditativo, nas quais as diferenças entre prosa e poesia tornam-se mais tênues e a métrica toma um caráter ao mesmo tempo menos marcado e mais fundamental. Após esse levantamento, propomos uma nova variação do verso branco em português, o dodecassílabo misto, composto de ritmo iâmbico, formado pela alternância de sílabas átonas e tônicas ou subtônicas, e dodecasílabos acéfalos quando o verso precedente é grave. Ilustramos nosso estudo do verso branco com passagens de The Prelude, de William Wordsworth, e traduzimos trechos da mesma obra segundo nossa medida métrica para determinar sua eficácia. Como resultado, notamos que nossa forma adaptada mostra-se capaz de acomodar aquelas qualidades consideradas essenciais ao verso branco, reformulando, em português, efeitos poéticos frequentemente perdidos no processo de versão de obras inglesas, como o ritmo regular binário e o momento de leitura vertido de um verso a outro de modo integrado. Concluímos, dessa maneira, que uma abordagem não-tradicional das potencialidades métricas da língua portuguesa, em diálogo com os moldes da poesia inglesa, é capaz de abrir novas perspectivas tradutórias para pesquisadores em língua portuguesa e trazer a lume qualidades de tradições métricas distintas que podem oferecer novas ferramentas a seus tradutores.
\end{abstract}

Palavras-chave: Verso branco. Métrica silábica-acentual. Tradução poética. Dodecassílabo iâmbico misto. Ritmo binário.

\begin{abstract}
The translation of epic blank verse usually takes two forms: formal adherence to syllabic counting as recreation of the pentameter as decasyllables, or semantic fidelity as adaptative transposition in free verse. Both modes cause detriment to the particular effects of the original form by not transposing to the target language the essential qualities of the English blank verse: the steady and constant rhythm and the tension between metric rhythm and the syntactic-semantic rhythm. In our essay we intended to study the qualities and effects that make epic blank verse distinct from other metrical forms, exploring the mechanisms of the iambic pentameter, its limits and mutations within the English tradition, and how this verse operates in unrhymed compositions of narrative and meditative character, in which the differences between prose and poetry becomes more subtle and the metric takes a character at the same time less marked and more fundamental. After this survey we propose a new variation of the blank verse in portuguese, the mixed dodecasyllable, composed of iambic rhythm, formed by the alternation between unstressed and stressed or half-stressed syllables, and headless dodecasyllables when the preceding verse possesses a feminine ending. We illustrate our study of the blank verse with excerpts from The Prelude, by William Wordsworth, and translate passages from the same work according to our metrical measure in order to determine its effectiveness. As a result we perceived that our adapted form appears to be capable of accomodating those qualities considered essential to the blank verse, reformulating in Portuguese poetic effects frequently lost during the process of translating English works, like the regular iambic rhythm and the reading momentuum poured
\end{abstract}


integrally from one verse to the next. We thus concluded that a nontraditional approach toward the metrical potentialities of Portuguese, in dialogue with the forms of English poetry, is capable of opening new perspectives of translation for Portuguese language researchers, and bringing to light qualities of different metrical traditions that can offer new tools to their translators.

Keywords: Blank verse. Accentual-syllabic meter. Poetic translation. Mixed iambic dodecasyllable. Binary rhythm.

RECEBIDO EM: 20 de agosto de 2019

ACEITO EM: 10 de dezembro de 2019

PUBLICADO EM: janeiro 2020 


\section{Introdução}

o buscar verter para o português o blank verse (verso branco) inglês, forma poética composta de pentâmetros iâmbicos não-rimados (versos decassilábicos de ritmo binário ascendente), o tradutor costumeiramente depara-se com duas opções: conservar o número de sílabas, e assim verter a composição nos moldes do verso branco português tradicional, seja em versos heroicos ou sáficos, como ambas as versões disponíveis em português do épico de John Milton, Paradise Lost, traduzidas por A. J. L. Leitão (Paraíso Perdido, 1840) e por Daniel Jonas (Paraíso Perdido, 2015), ou prescindir da forma métrica a fim de atingir maior fidelidade semântica em versos livres, como as traduções para o português de The Prelude, de William Wordsworth, em versão integral por Maria de Lourdes Guimarães (O Prelúdio, 2010) e parcial por John Milton (publicado em O Olho Imóvel Pela Força da Harmonia, 2007). Ambas as posições, porém, não preservam a qualidade fulcral do verso branco inglês, como identificada pela crítica especializada da forma: sua estrutural tensão entre ritmo sintático e métrico, entre dicção prosaica e poética, entre verso e oração como unidades mínimas de sentido e leitura. $\mathrm{O}$ decassílabo tradicional português não possui um padrão métrico rigoroso o suficiente para constituir um ritmo métrico autônomo e distinto da sintaxe que carregue a leitura com a mesma cadência ininterrupta do verso inglês, e o verso livre, por sua vez, além de perder o ritmo binário basilar do verso branco, torna-o quase que indistinguível da prosa.

Contrariamente a essas duas proposições de tradução, buscamos, neste artigo, compreender os mecanismos e as particularidades do verso branco a fim de determinar quais características o tornam distinto de outras espécies de versos e quais aspectos seus devem ser preservados em uma tradução a fim de que os mesmos efeitos produzidos pelo ritmo original possam ser reproduzidos em português. Com esse fim, tomamos como exemplo de análise o verso branco épico pós-miltoniano de The Prelude (1850), do poeta inglês William Wordsworth, o mais importante renovador da forma após John Milton. Primeiramente, estudaremos a constituição fundamental do verso branco no pentâmetro iâmbico através das considerações de Derek Attridge (1999) e David Keppel Jones (2001), ilustrando-as com exemplos de Wordsworth. Em seguida, analisaremos as qualidades do verso branco propriamente, especialmente no que tange ao caráter unitário e cumulativo de seu ritmo, derivado do padrão iâmbico e uso de enjambement, como argumentam os críticos John Symonds (1895), Robert Shaw (2007) e Henry Weinfield (2012). Por fim, delinearemos algumas questões e desafios suscitados pelo trabalho de tradução do verso branco e proporemos 
uma solução alternativa para sua versão, a qual possa abarcar suas qualidades originais e reproduzir, dentro das potencialidades da língua portuguesa, o ritmo da forma inglesa.

\section{0 pentâmetro iâmbico}

O verso branco possui por base o pentâmetro iâmbico (iambic pentameter), verso constituído, modelarmente, de cinco iambos, isto é, pés métricos formados por uma sílaba átona (unstressed) sucedida de uma sílaba tônica (stressed), totalizando, portanto, um verso de dez sílabas. Tomamos por ilustração alguns versos de The Prelude e sua escansão (o sinal “_" marca sílabas átonas e “"”, sílabas tônicas):

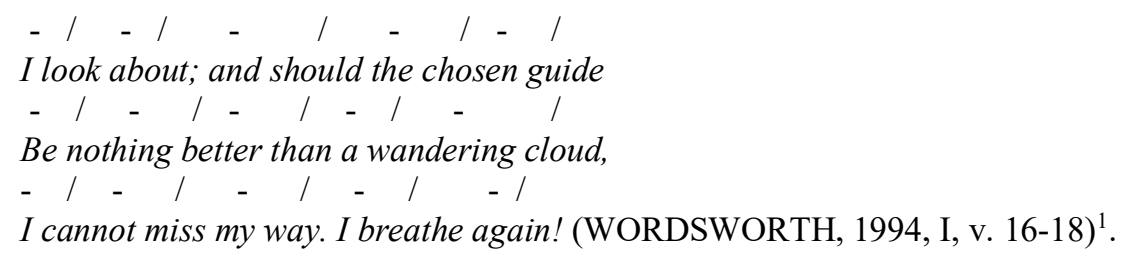

Aqui percebemos, como descrito, que todos os versos obedecem rigorosamente ao padrão

14 métrico: dez sílabas cada (na segunda, ocorre elisão da segunda sílaba em wandering wand'ring para que a contagem seja mantida regular) e ritmo ascendente (be NO-thing BE-tter THAN [...]). Porém, à parte versos exemplares como esses, The Prelude oferece outros tantos que desviam do ritmo esperado, como em sua abertura:

\section{O There is blessing in this gentle breeze, (WORDSWORTH, 1994, I, v. 1) $)^{2}$.}

Em que ocorre uma inversão trocaica do iambo inicial (o ritmo ascendente do iambo "- /" é substituído pelo ritmo descensional do troqueu “/ -") e a elevação enfática de um sílaba átona ("in") ao nível de tônica (ou subtônica, "half-stress", indicado por ")"), recebendo ênfase por encontrar-se na posição de acentuação métrica (sílaba par, $6^{\circ}$ ) e entre duas outras sílabas átonas ("-ing" e "this"). Ou, ainda, encontramos versos que parecem negligenciar de todo a estrutura métrica, como

From that soft couch I rose not, till the sun (WORDSWORTH, 1994, I, v. 86) ${ }^{3}$.

o qual, embora conservando o número de sílabas e as cinco tônicas obrigatórias, deixa a cargo da própria sintaxe, ao invés da métrica, a disposição de sua organização rítmica. Não obstante, as variações apresentadas (e outras mais) fazem parte elementar da tradição inglesa do 
pentâmetro iâmbico desde a adoção deste pelos poetas renascentistas; são elas, de fato, que emprestam variedade e vigor renovado a um verso que de outra forma permaneceria marcadamente monotônico pela adesão estrita à regularidade métrica, e são os desvios rítmicos que, em especial, contribuem com o caráter de naturalidade, de maior conformidade com a linguagem real, que o pentâmetro iâmbico apresenta em relação a outras espécies de versos fixos.

É desse modo que o crítico inglês Derek Attridge, em sua obra The Rhythms of English Poetry (1982), descreve o verso pentamétrico, notando que "o pentâmetro é caracterizado por sua variedade rítmica, possibilitando o movimento natural da fala ser imitado ou acentuado conforme a determinação do poeta" (ATTRIDGE, 1999, p. 132, tradução nossa) ${ }^{4}$. De fato, ele é, segundo o crítico, a única forma métrica simples que se distancia do ritmo tetramétrico e sua associação com a balada e a canção, prestando-se melhor, portanto, a versos mais ambiciosos (ATTRIDGE, 1999, p. 124). Essa característica deve-se ao fato de que o pentâmetro compõe um todo rítmico próprio, não tendendo a agrupamentos maiores do que o próprio verso, como é o caso do tetrâmetro, que tende a se atualizar ritmicamente na forma de pares de versos, os quais, por sua vez, formam a popular quadra das baladas. O pentâmetro, portanto, segundo Attridge,

\footnotetext{
não traz consigo o senso de um forte ritmo subjacente; ele observa a acentuada regularidade de movimento criada pela alternância de sílabas tônicas e átonas, sem que aquelas pulsações rítmicas se agrupem consistentemente $-\mathrm{e}$ insistentemente $-\mathrm{em}$ pares e quadras, e sem nenhuma tendência para que ritmos dipódicos se façam patentes. Por essa razão, ele soa ao ouvido como mais fiel ao ritmo natural da fala: não é que grupos pentamétricos sejam de alguma forma indígenas ao inglês, mas é que tais grupos impõem-se menos marcadamente sobre o movimento da linguagem. Em outras palavras, pentâmetros exibem uma relação diferente entre os dois princípios rítmicos que colaboram na criação da forma métrica: o ritmo da língua fala mais alto, a forma rítmica elementar, mais baixo (ATTRIDGE, 1999, p. 126, tradução nossa) $)^{5}$.
}

Diferente do tetrâmetro, o pentâmetro não apresenta um ritmo tão marcado e, por esse motivo, deixa o ritmo natural da linguagem dominar, o que torna essa forma particularmente adequada a composições de fôlego, como dramas e narrativas. Ademais, como Attridge argumenta, o poeta que opta pelo pentâmetro por razão de seu afastamento de versos mais musicais frequentemente adotará atualizações rítmicas que aproximem seus versos da linguagem falada, como o uso de ritmo ascendente ao invés de descendente, ritmo duplo ao invés de triplo, enjambement, ausência de rima e alternância dipódica. Dessa forma, o pentâmetro tende a se 
atualizar de forma quase universal (com raros desvios) como um verso de cinco batidas, com ritmo binário e introduzido por uma sílaba átona: em resumo, o ritmo iâmbico.

$\mathrm{Na}$ mesma esteira, Attridge argumenta que a já referida independência formal do pentâmetro, sua tendência a não constituir agrupamentos rítmicos maiores que o próprio verso, possui importantes implicações no que diz respeito à relação entre os versos, pois

mesmo quando estão organizados por rimas na forma de estrofes, os versos retêm suas identidades separadas como grupos pentamétricos. Isso significa que, quando alcançamos o fim do verso, não há uma pressão causada pela estrutura maior para se registrar a conclusão de uma unidade rítmica e proceder para a próxima. Em vez disso, a sintaxe tem uma voz mais poderosa - outro exemplo da relação menos dominante do ritmo pentamétrico com a linguagem - e determinará se pausamos ou seguimos lendo o verso seguinte. $O$ pentâmetro que sistematicamente nos encoraja a pausar ao fim do verso será, é claro, marcado por ritmos mais fortes, já que a unidade quinária de batidas será destacada; o uso liberal de encavalgamentos, por outro lado, criará um movimento contínuo em que a divisão entre linhas pode não ser muito aparente (ATTRIDGE, 1999, p. 133, tradução nossa) ${ }^{6}$.

É o ritmo sintático, portanto, que predomina sobre a métrica no caso do pentâmetro. Essa relação torna tal verso um instrumento dotado de versátil maleabilidade na mão de poetas que 16 desejem explorar as potencialidades poéticas da linguagem natural. A mesma relação, porém, gera no íntimo do verso uma tensão entre linguagem poética e prosaica que desestabiliza o limite entre ambas, particularmente no caso do verso branco (não rimado). No centro dessa questão, está a ambivalência rítmica da pausa final do pentâmetro. Esta é, segundo Attridge, em certo sentido, extramétrica, pois, sendo o pentâmetro uma unidade independente, não há um impulso inerente à estrutura do ritmo (como ocorre no tetrâmetro) que conduza a leitura diretamente ao verso seguinte; antes, é a sintaxe, a presença ou ausência de enjambements que determinará a qualidade da pausa ao fim do verso, se a leitura deve se demorar nela ou ignorála. A maior liberalidade com que o pentâmetro recebe enjambements, por sua vez, torna a forma mais propícia para a formação de composições não rimadas.

Por fim, Attridge enfatiza o papel desempenhado pelo ritmo silábico na estrutura do pentâmetro. Como argumenta o autor, como o pentâmetro é um padrão menos marcado e menos prontamente reconhecível, ele exige um controle rigoroso das disposições dos elementos rítmicos para que seja conservado sem desmantelar-se em verso livre. Assim, a alternância de sílabas átonas e tônicas do iambo deve ser mantida de forma quase completamente regular, caso se deseje manter reconhecível o ritmo subjacente. Por outro lado, dentro de uma sucessão de pentâmetros, contanto que a regularidade da alternância de ênfases seja mantida, um verso com um pé a mais ou a menos será incorporado sem maiores perturbações na estrutura rítmica total. 
Não obstante, enquanto o pentâmetro exige a regularidade rítmica para conservar-se, são de igual importância à forma as variações métricas consagradas pela tradição do emprego do verso, das quais se valem seus poetas para solucionar problemas prosódicos e para infundir vitalidade no verso. David Keppel Jones, em The Strict Metrical Tradition (2001), delineia esse conjunto de variações, as quais vieram a compor o cânone de possibilidades métricas empregadas desde os autores renascentistas, que as estabeleceram, até os poetas românticos. Esse conjunto de "modos segundo os quais o padrão acentual alternante das sílabas pode variar" (JONES, 2001, p. 4, tradução nossa) ${ }^{7}$, forma, segundo Jones, a técnica poética que deu versatilidade ao pentâmetro iâmbico e proporcionou a ele estabelecer-se como uma tradição ininterrupta de quase 300 anos.

O pentâmetro iâmbico regular (unvaried) é definido por Jones como verso sem variação específica de ênfase e sem sílabas extras e no qual as sílabas ímpares são átonas e as pares, tônicas. O verso é ainda considerado regular quando sílabas subtônicas estão presentes tanto no caso de sílabas pares quanto ímpares. Assim, o ritmo alternante do iambo é identificado pela oposição de ênfase entre sílabas sucessivas, em que uma sílaba tônica é percebida como uma batida do ritmo pelo fato de ser precedida de uma sílaba átona. Dessa forma, Jones descreve o processo pelo qual o ritmo iâmbico é percebido:

em cinco pontos, nas sílabas de numeração ímpar, não apenas reconhecemos uma
sílaba tônica como tal mas percebemos que ela foi devidamente precedida e
introduzida por uma sílaba átona. Esse momento de reconhecimento coincide com o
impulso muscular de enunciação da sílaba tônica (em voz alta, ou como se fosse), o
qual, por sua vez, cria a sensação de uma batida. Assim, a feliz coincidência surge
pela qual a sílaba tônica provê um ponto focal para um ato singular de percepção
rítmica abarcando duas sílabas. Com cada ato desses, mesmo enquanto a batida é
registrada, a notação daquela unidade rítmica com suas duas sílabas é encerrada; e a
notação da próxima unidade está pronta para proceder de um novo começo. Com um
novo começo e com apenas duas sílabas a serem processadas, cada passo nesse
processo iâmbico básico pode ser conduzido quase inconscientemente (JONES, 2001,
p. 35-36, tradução nossa) ${ }^{8}$.

Jones distingue duas espécies de variações. A primeira ele denomina como "variações simples", que se apresentam como duas versões: ou como a presença de uma sílaba átona (weak) onde uma sílaba tônica (strong) era esperada (como exemplifica o verso de Wordsworth

A tempest, a redundant energy, (WORDSWORTH, 1994, I, v. 37) ${ }^{9}$, 
onde o artigo “ $a$ ", apesar de ser uma sílaba átona, recebe o acento métrico [indicado por *] devido à sua posição de sílaba par no verso); ou como a presença de uma sílaba tônica onde uma átona era esperada (como no verso

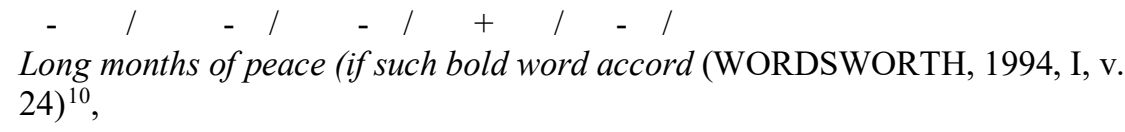

onde o adjetivo "bold" sofre leve rebaixamento de sua acentuação [indicada por + ] devido à sua posição de sílaba ímpar). Jones, entretanto, dá maior importância à segunda espécie de variações, que nomeia como "variações radicais", aquelas que perturbam o padrão de alternância do pentâmetro iâmbico. O primeiro e mais comum tipo de variação dessa espécie é a "inversão trocaica" (ou, simplesmente, "inversão"), a qual consiste na substituição de um iambo (-/) por um troqueu (/ -). Jones, no entanto, identifica a inversão como parte de uma figura maior, a do coriambo, composto de quatro sílabas, um troqueu seguido de um iambo, como no verso

Onde o primeiro pé (local onde geralmente ocorre inversão) apresenta ritmo descendente, ao invés de ascendente, e é seguido por um retorno ao ritmo padrão. A segunda variação identificada por Jones é o iônico menor, figura métrica composta de duas sílabas átonas seguidas de duas tônicas:

For I, methought, while the sweet breath of heaven (WORDSWORTH, 1994, I, v. $33)$.

A terceira variação consiste no uso do segundo epitrito, composto de uma sílaba tônica, seguida de uma átona e duas tônicas:

Days of sweet leisure, taxed with patient thought (WORDSWORTH, 1994, I, v. 43).

Essas três figuras, portanto, o coriambo, o iônico menor e o segundo epitrito, formam, segundo Jones, o cânone de inversões permitidas dentro do que o crítico denomina a "tradição de métrica estrita", abrangendo o período de 1590 a 1865 da tradição do pentâmetro iâmbico na Inglaterra. 
Constatamos, desse modo, a partir das observações de Attridge e Jones, que o ritmo iâmbico é necessária e consistentemente regular, marcado sempre pela alternância de ênfases silábicas de forma binária. Por outro lado, no entanto, a qualidade das ênfases é variável, aceitando sílabas subtônicas no lugar de tônicas e promoções e rebaixamentos de acentuações. Tal característica do pentâmetro iâmbico torna essa forma mais adequada a composições poéticas mais próximas do registro linguístico prosaico e, portanto, o metro que se adequa mais naturalmente a poemas não-rimados, como é o caso do verso branco.

\section{0 verso branco}

Segundo o crítico John Symonds, em sua obra seminal Blank Verse (1895), o verso branco inglês é um dos metros mais variados e plásticos disponíveis na língua, sendo capaz de se adequar "às mais triviais e às mais sublimes elocuções" (SYMONDS, 1895, p. 16, tradução nossa $)^{12}$. Assim como o pentâmetro iâmbico, e por ser fundado nele, o verso branco "deve sua beleza às liberdades tomadas com a estrutura normal" (SYMONDS, 1895, p. 1, tradução nossa $)^{13}$, liberdades essas que são explicadas se considerarmos "a inflexão requerida pela significância retórica dos versos anormais" (SYMONDS, 1895, p. 2, tradução nossa) ${ }^{14}$. O crítico ademais argumenta que, tendo sua origem no palco, o verso branco deriva sua força e liricismo (e evade a monotonia em que pode facilmente cair) mais do impulso retórico de seu próprio conteúdo do que de questões formais, pois "sendo um metro acentual, o verso branco deve muito de sua qualidade rítmica à ênfase" (SYMONDS, 1895, p. 12, tradução nossa) ${ }^{15}$. Assim, a escritura e leitura do verso branco se fundam em um duplo efeito de variedade e unidade, metro e ritmo sintático-semântico, pois “o verdadeiro segredo do verso branco consiste na adaptação adequada de palavras e ritmos ao sentido contido neles" (SYMONDS, 1895, p. $50-51$, tradução nossa) ${ }^{16}$. Segundo o autor, o verso branco é uma forma especialmente adaptada para registrar o pensamento em desenvolvimento, ao que atesta seu uso mais extensivo (e mais bem sucedido) na poesia dramática, épica e meditativa, e, como tal, prescindindo a organização estrófica de outras formas consagradas, possui uma estruturação mais expansiva e maleável, subordinada ao período e ao pensamento, disto decorrendo que, muitas vezes, a musicalidade de um verso depende da cadência daquele que o precede. Dessa forma, Symonds define o verso branco como uma forma que opera em duas camadas: uma patente, "determinada pelo sentido e entonação do pensamento do poeta" (SYMONDS, 1895, p. 64, tradução nossa) ${ }^{17}$, outra virtual, na qual "o compasso decassilábico mantém uma subcorrente de pulsações regulares" (SYMONDS, 1895, p. 64, tradução nossa) ${ }^{18}$. 
Na mesma esteira de Symonds, Robert Shaw, em Blank Verse: a guide to its history and use (2007), afirma que uma das qualidades essenciais desse verso é o fato de que ele “tipicamente atinge seus efeitos mais memoráveis não em um único verso, mas cumulativamente" (SHAW, 2007, p. 26, tradução nossa) ${ }^{19}$, o que suscita no poema "um momentum imperioso, [uma] sensação de movimento ininterrupto, que é uma das mais importantes características (e vantagens) do verso branco" (SHAW, 2007, p. 4, tradução nossa) $)^{20}$, o que Milton, em seu prefácio a Paradise Lost, descreve como "o sentido variadamente vertido de um verso a outro" (MILTON, 2005, p. 1, tradução nossa) ${ }^{21}$. Da mesma forma que Symonds, Shaw evoca a dupla lógica operante no verso branco, sua tensão entre rigidez e liberdade, entre metro fixo e ritmo retórico, e sublinha:

liberdade e fixidez estão ambas em jogo na forma. Não coibido e não segmentado por padrões de rima, ele [o verso branco] pode acomodar fluxos prodigiosos de elocução; nesse sentido, ele é mais livre. Ao mesmo tempo, diferente do verso livre, ele tem uma extensão de verso fixa e um número de pulsações recorrente, e, enquanto poetas praticantes podem admitir ritmos flexíveis e mesmo substituições métricas ocasionais, essas obtêm poder expressivo precisamente porque o pentâmetro iâmbico padrão está lá como uma base, um ponto do qual se pode variar (SHAW, 2007, p. 4; grifo do autor, tradução nossa) ${ }^{22}$.

Desse modo, percebemos como uma sequência de versos que siga estritamente o metro arriscará cair em monotonia, enquanto que variações acentuais e métricas que acompanhem naturalmente o ritmo semântico poderão conferir maior vitalidade ao verso, sem detrimento à forma. Tais variações, como vimos, são consagradas pela tradição do pentâmetro iâmbico e contribuem para o duplo efeito de variedade e regularidade rítmica característico do verso branco.

Em outra perspectiva, mas partindo da mesma apreciação da forma, Henry Weinfield, em sua obra The Blank Verse Tradition from Milton to Stevens: freethinking and the crisis of modernity (2012), considera o significado histórico-político do verso branco e sua relação próxima com noções de livre-pensamento e, mesmo, revolução. Segundo o autor, o verso branco encontra-se em um estado intermediário entre o verso formalmente rimado e a prosa, entre, portanto, os registros e experiências do "poético" e do "prosaico". Essa localização e livre locomoção entre dois mundos, tanto no que diz respeito à forma quanto à temática, dá ocasião a uma liberdade particular ao verso branco, liberdade esta que "primeiro em Milton e, então, nos poetas românticos e modernos que o seguem nessa forma, parece permitir e promover o que costumava ser chamado de livre-pensamento" (WEINFIELD, 2012, p. 2, grifo do autor, tradução nossa) ${ }^{23}$. Weinfield sugere ainda que a própria liberdade formal do verso branco (seu 
"movimento ininterrupto", na expressão de Shaw) torna o verso branco propício a formas mais adequadas aos meandros do pensamento especulativo, como o poema discursivo, narrativo ou meditativo. Dessa forma, desde sua adoção por Milton, o verso branco carrega em seu emprego um posicionamento político e intelectual que deve ser levado em consideração da mesma forma que seus aspectos prosódicos. De fato, os aspectos político e prosódico não devem ser considerados separadamente, pois é a própria variabilidade rítmica do verso branco, sua heterogeneidade prosódica, que o torna capaz de adequar-se a registros linguísticos distintos do canonicamente "poético".

Podemos concluir, portanto, a partir das observações dos três autores consultados, que o verso branco é fundamentalmente composto de duas correntes rítmicas divergentes e complementares: uma, patente, derivada do ritmo natural da linguagem e sua disposição sintático-semântica e subordinada à duração da frase para além da unidade do verso, e outra, virtual, derivada do ritmo métrico do pentâmetro iâmbico e circunscrita pelos limites do verso, mas formando também um encadeamento rítmico de iambos que transborda naturalmente de um verso a outro.

\section{Adaptação do metro}

É desejando conservar as características supracitadas do verso branco que consideramos as abordagens tradicionais de sua tradução insuficientes e propomos uma nova forma métrica. Em um extremo, apresenta-se a opção tradutória de seguir a rigor a quantidade silábica do verso original, isto é, dez sílabas, transpondo-se o pentâmetro iâmbico para o metro tradicionalmente equivalente em português, o decassílabo, seja heroico ou sáfico. Em outro extremo, encontramos a opção de prescindir de métrica regular e adotarmos o verso livre, dando consideração apenas a questões estilísticas e semânticas. Ambas, porém, a estrita aderência à correspondência silábica ou à fidelidade sintático-semântica geram deficiências tradutórias que excedem qualquer ganho pretendido e, além do mais, baseiam-se em falsas premissas semióticas do que está implicado na versão da forma e do sentido de um poema para outra língua.

O postulado da equivalência métrica falha, primeiramente, ao dar maior relevância a elementos formais superficiais, como a contagem de sílabas, à despesa do estilo e vocabulário. Frequentemente, a fim de que um verso decassilábico inglês se adeque ao decassílabo português, o tradutor deverá lançar mão das mais diversas adaptações e sacrifícios, como o constante recurso a palavras mono- e dissilábicas, as quais, invariavelmente, pertencem ao 
registro elevado ou arcaizante, o que torna difícil manter o registro coloquial e vocabulário prosaico que definem o estilo de um poeta como Wordsworth. Na mesma esteira, o tradutor vêse obrigado a usar alto número de inversões sintáticas e enxugamentos lexicais que perturbam não apenas o ritmo sintático, mas também o ritmo semântico.

Um exemplo no qual torna-se perceptível as faltas desse paradigma tradutório é a tradução de Paradise Lost pelo português António José de Lima Leitão (Paraíso Perdido, 1840):

Quadro 1 - Comparação entre original de Paradise Lost e versão ao português de Leitão

\begin{tabular}{|c|c|}
\hline $\begin{array}{c}\text { Paradise Lost (MILTON, 2005, v. 1-4) } \\
\text { [versão original] }\end{array}$ & $\begin{array}{c}\text { Paraíso Perdido (MILTON, 1840, v. 1-4) } \\
\text { [Traduzido por: A. J. L. Leitão] }\end{array}$ \\
\hline 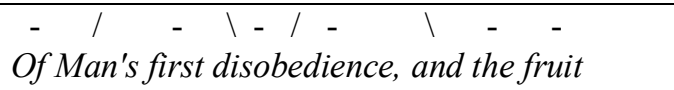 & 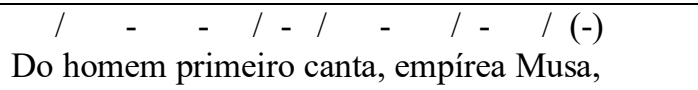 \\
\hline 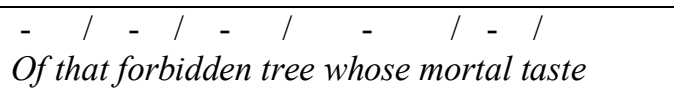 & 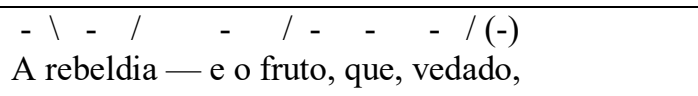 \\
\hline 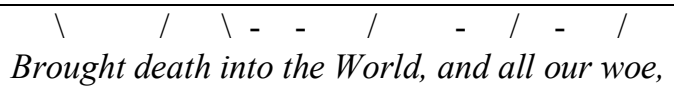 & 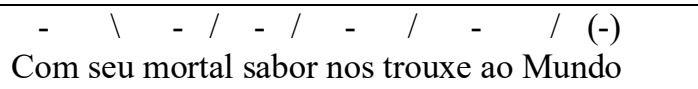 \\
\hline 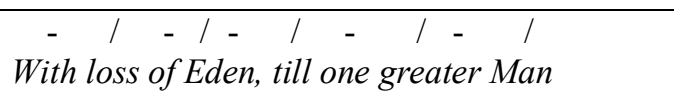 & 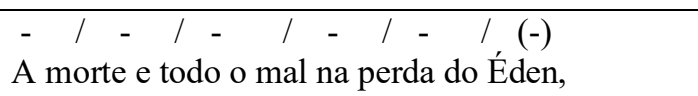 \\
\hline
\end{tabular}

Fonte: Milton (2005); Milton (1840).

Percebemos, a partir do cotejamento entre o original inglês (à esquerda) e a tradução em português (à direita), que houve ganhos e perdas decorrentes das opções tradutórias. Da adesão ao metro tradicional decassilábico resultou um verso regular e de ritmo agradável, em muitas instâncias semelhante ao próprio compasso iâmbico do original. Porém, a necessidade de manter-se limitado à mesma quantidade de sílabas do texto fonte forçou o tradutor, por um lado, ao deslocamento de elementos de um verso para outro, como: "empírea Musa" ("Heavenly Muse"), transplantado do sexto verso para o primeiro; "rebeldia" ("disobedience"), do primeiro para o segundo; "Nos trouxe ao Mundo / A morte e todo o mal", uma recomposição segmentada e deslocada do original "Brought death into the World, and all our woe"; e, por outro lado, à substituição (com suas implicações semânticas e de valor poético) de "the fruit / Of that forbidden tree" por "fruto que vedado". Desse modo, percebemos como a limitação do decassílabo invariavelmente exigem sacrifícios que, em grau baixo ou elevado, descaracterizam a estrutura do texto original.

Por outro lado, a opção pelo verso livre, ainda que remediasse as deficiências supracitadas, falha por conceber a métrica como mero adorno poético, dispensável frente ao 
aspecto mais fulcral do sentido. O metro, porém, é elemento significante tanto positivamente, por ligar composições poéticas dentro da tradição de um verso, o qual por virtude dessa tradição, ativa o repertório do leitor, suscitando neste memórias afetivas e expectativas emocionais e estilísticas, como também gera significado negativamente, pondo em oposição metro fixo e ritmo variável. Sem o rigor da métrica, diversas passagens de The Prelude que beiram a raia do mero prosaísmo perderiam o sustento que lhes empresta o impulso rítmico do pentâmetro iâmbico, enquanto trechos de alto liricismo se destacariam do texto como matéria heterogênea. É em virtude da constância métrica que Wordsworth é capaz de harmonizar registros tão díspares como aqueles que se encontram em seu texto.

Como exemplo desse paradigma, podemos observar a tradução realizada por Maria de Lourdes Guimarães de The Prelude (O Prelúdio, 2010):

Quadro 2 - Comparação entre original de The Prelude e versão ao português de Guimarães

\begin{tabular}{|c|c|}
\hline $\begin{array}{c}\text { The Prelude (WORDSWORTH, 1994, v. 1-4) } \\
\text { [versão original] }\end{array}$ & $\begin{array}{c}\text { O Prelúdio (WORDSWORTH, 2010, v. 1-4) } \\
\text { [Traduzido por: M. L. Guimarães] }\end{array}$ \\
\hline 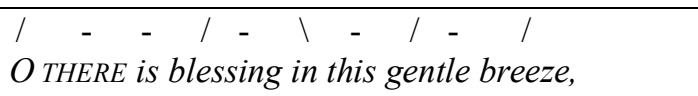 & $\begin{array}{c}-\quad \backslash-\quad / \quad-\quad-/ / \\
\text { Oh, uma bênção existe nesta doce brisa, }\end{array}$ \\
\hline 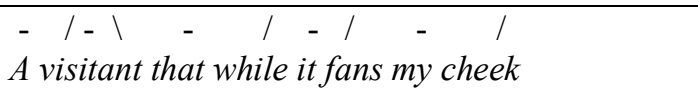 & 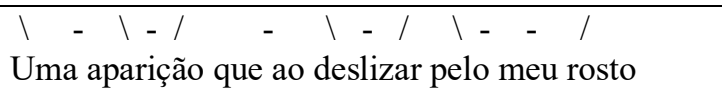 \\
\hline 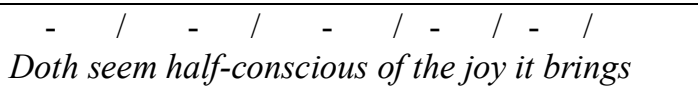 & $\begin{array}{c}/--/--/--/-\quad-/ \\
\text { Quase parece sentir a alegria que traz }\end{array}$ \\
\hline $\begin{array}{cccccccc}- & - & / & / & - & - & / & -\end{array}$ & 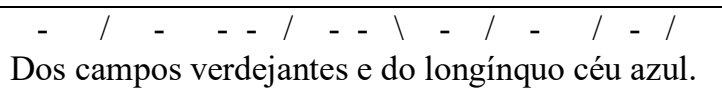 \\
\hline
\end{tabular}

Fonte: Wordsworth (1994); Wordsworth (2010).

Analisando sua versão do ponto de vista da métrica binária do iambo, percebemos que seu ritmo não apresenta uma coesão análoga àquela que subjaz ao texto original. A pluralidade de pés utilizados (ou que são apreendidos pelo leitor) torna fragmentária a leitura, visto que o leitor deve conceber cada verso como uma unidade rítmica distinta das anteriores e sucedentes. A isso concorre, especialmente, a variabilidade de extensão dos versos, como observamos na passagem do terceiro (13 sílabas) ao quarto (15), uma opção estilística em oposição aos efeitos produzidos pelo enjambement que acopla os versos ("brings / From [...]”). Além disso, a tradutora, a fim de conservar o elemento poético do texto, perdido, em parte, com a exclusão da métrica, deve valer-se de vocábulos mais marcadamente poéticos, como "verdejantes" e "longínquo", para traduzir termos que, no original, derivam seu valor precisamente de seu 
prosaísmo, "green" ("verde") e "yon" ("aquele"), o que furta ao texto seu caráter de poema épico escrito linguagem comum.

Tendo em vista os limites e deficiências dessas duas formas, decidimos por adotar como base o verso dodecassilábico (alexandrino), o qual, segundo Lawrence Pereira, "presta-se perfeitamente às formas mais ritmadas assim como às formas conversacionais, reflexivas e disruptivas" (PEREIRA, 2015, p. 47), bem como à "flutuação entre o hiperpoético e o conversacional, evitando uma ritmação excessivamente audível” (PEREIRA, 2015, p. 47). Ainda, segundo Pereira, o alexandrino "permite, na tradução em verso, uma reprodução dos lexemas específicos do original, assim como das suas peculiaridades sintáticas, diminuindo assim o procedimento invasivo e agressivo de reconfiguração genérica do sentido" (PEREIRA, 2017, p. 123). De um ponto de vista prático, as duas sílabas a mais de que o alexandrino dispõe dão um maior espaço de manobra ao tradutor, o que lhe permite evitar as armadilhas do decassílabo.

Em uma questão mais sutil, o dodecassílabo está mais apto a traduzir o pentâmetro inglês devido à maior equivalência entre essas duas formas no que diz respeito ao volume semântico e à duração prosódica. Por volume semântico, compreendemos a quantidade de elementos significantes que um verso comporta, o que não raro coincide com a quantidade de palavras em um verso. Embora uma avaliação precisa da diferença de volume semântico entre o decassílabo inglês e o português requereria um estudo linguístico de fôlego, contentamo-nos com a observação fundamental de que, simplesmente, o decassílabo inglês comporta mais palavras do que o português. Isso é importante tomar em consideração, pois, aparte as consequências que esse fato levanta para a tradução do sentido e do estilo, possui consequência também sobre o que podemos chamar de "duração semântica" do verso. Enquanto o leitor do decassílabo inglês deverá frequentemente demorar-se sobre o sentido de 9 ou 10 vocábulos por verso, o leitor do decassílabo português, através do mesmo número de sílabas, encontrará menos unidades de sentido e, portanto, realizará uma leitura mais rápida. Desse modo, se a proporção sema/sílaba do verso inglês é amiúde mais uniforme, faz-se necessário emprestar ao verso português um número maior de sílabas, para que se possa alocar em um verso traduzido o mesmo número (ou quase) de vocábulos presentes no original, e assim reconstruir um verso com o mesmo volume (ou gravidade) semântico.

A adição de sílabas, por outro lado, não promoverá uma prolongação excessiva da duração prosódica do verso. De fato, ela compensará a escassa quantidade de sílabas tônicas que o verso português apresenta em comparação com o inglês. Se é costumeiro do leitor 
apressar-se sobre sílabas átonas e demorar-se nas tônicas, naturalmente o verso português, que apresenta, proporcionalmente, mais daquelas do que destas, será sentido como mais rápido e, consequentemente, mais "leve" que o inglês, perdendo parte da "gravidade" que este recebe de suas sílabas longas (distinção praticamente ausente no português). Com a adição de duas sílabas, tornando, portanto, o decassílabo em dodecassílabo, é possível compensar a diferença de duração prosódica do verso entre as duas línguas.

Assim, determinamos o alexandrino como o verso mais adequado a reproduzir a gravidade poética do pentâmetro inglês. Seu ritmo tradicional, com acentuação na $6^{\mathrm{a}}$ e $12^{\mathrm{a}}$ sílabas, ou mesmo versões mais modernas do dodecassílabo, de acentuação na $4^{\mathrm{a}}, 8^{\mathrm{a}}$ e $12^{\mathrm{a}}$, se acomoda facilmente à lírica, de composição mais concisa e na qual a rima conserva o ritmo mais marcadamente dentro dos limites do verso, e ao teatro, no qual os ritmos conversacional e retórico sobrepõem-se à métrica. No caso do verso branco épico, no entanto, em que o ritmo iâmbico é sentido cumulativamente e sua cavalgada impele a leitura com um momento ininterrupto, espraiando-se ao longo de numerosos versos, o efeito de unidade rítmica (ao que os poemas de Milton e Wordsworth devem boa parte de sua força) não é conseguido senão com uma atenção precisa ao metro, o que exige do tradutor uma recriação do iambo dentro das potencialidades da língua portuguesa.

Mas a recriação do metro iâmbico é oposta por diversas complicações. Em inglês, como o vocabulário é composto em sua maioria de palavras mono- e dissilábicas, torna-se mais fácil manter a alternância entre sílabas átonas e tônicas do iâmbico. Em português, por outro lado, no qual há maior quantidade de palavras polissilábicas, a formatação do ritmo ao iâmbico, concebido de forma estrita (como alternância de átonas e tônicas), mostra-se uma tarefa impossível ou, ao menos, indesejável, visto que requereria o constante recurso a vocábulos raros e construções sintáticas artificiais. Da mesma forma, caso primássemos pelo iambo estrito, apesar de todos os sacrifícios estilísticos necessários à sua formulação, ainda assim o verso mostrar-se-ia indesejável, pois o ritmo tornar-se-ia excessivamente marcado e artificial, e não daria espaço para o jogo entre metro e ritmo linguístico tão característico do verso branco.

A solução reside na própria arte métrica dos poetas ingleses, especialmente como se apresenta no verso branco de Wordsworth. Tradicionalmente, o pentâmetro iâmbico recebe variabilidade pelo uso de acentos subtônicos e da promoção e rebaixamento de acentos, e, usando essas mesmas ferramentas, podemos recriar o ritmo em português. Assim, tomamos palavras, como "peregrino", como possuindo um acento subtônico e um tônico e formando, portanto, um ritmo alternante trocaico (pe-re-GRI-no; $\backslash$ - / -); da mesma forma, palavras como 
“imaginar", se considerarmos a subtônica, possuem ritmo iâmbico (i-ma-gi-NAR; - \- /). A subtônica recebe expressividade rítmica devido ao contraste alternante entre acentos silábicos. Este é construído cumulativamente de modo a formar uma corrente rítmica subterrânea que se imprime na expectativa do leitor, causando a natural promoção ou atenuação do acento em sílabas de qualquer espécie por força de sua posição na cadeia de alternância acentual. Assim, a palavra "não", por exemplo (em nossa tradução de The Prelude), receberá valor acentual de acordo com a qualidade das sílabas precedentes e sucedentes (como Jones caracteriza o funcionamento iambo), sendo, portanto, ora átona,

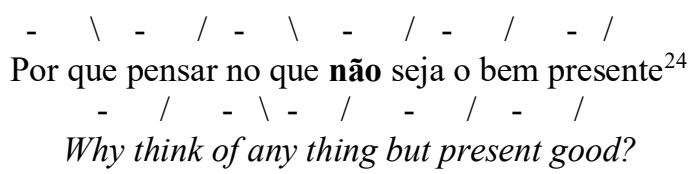

ora tônica

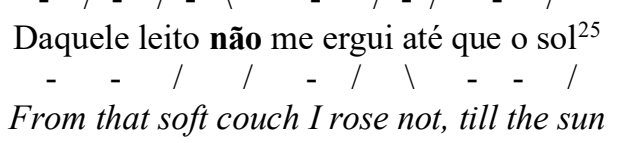

Utilizando as variações acentuais mencionadas, pudemos criar um verso dodecassilábico iâmbico de cadência constante, mas natural, com métrica fixa atualizada em versos de prosódia particular. Porém, deparamo-nos com novo problema ao buscarmos reproduzir a cadência constante do verso iâmbico na escala do parágrafo poético, particularmente na presença de enjambement. A dificuldade consistiu, novamente, na diferença silábica entre o léxico inglês e português. Enquanto o inglês apresenta uma maior quantidade de oxítonas, fazendo de versos graves ocorrências mais raras, o volume de palavras paroxítonas em português torna inevitável a presença de versos graves. Disto decorre que o ritmo iâmbico é quebrado pela sílaba extra na passagem de um verso grave para o seguinte. A solução consistiu em considerar a sílaba extra como parte integrante da cadeia rítmica, como sílaba átona a ser seguida por uma tônica no começo do verso seguinte (ou uma átona, caso seja possível elisão), formando um iambo repartido entre dois versos. Dessa forma, estipulamos que a forma métrica ideal para a versão do verso branco épico é a do que nomeamos como "dodecassílabo iâmbico misto", isto é, versos de doze sílabas de ritmo iâmbico, formados pela alternância entre sílabas átonas e tônicas ou subtônicas, as quais são suscetíveis de promoção ou rebaixamento acentual segundo sua posição e a qualidade das sílabas circundantes, em que versos graves são seguidos 
de dodecassílabos iâmbicos acéfalos, ou seja, versos de onze sílabas de ritmo trocaico, como na passagem:

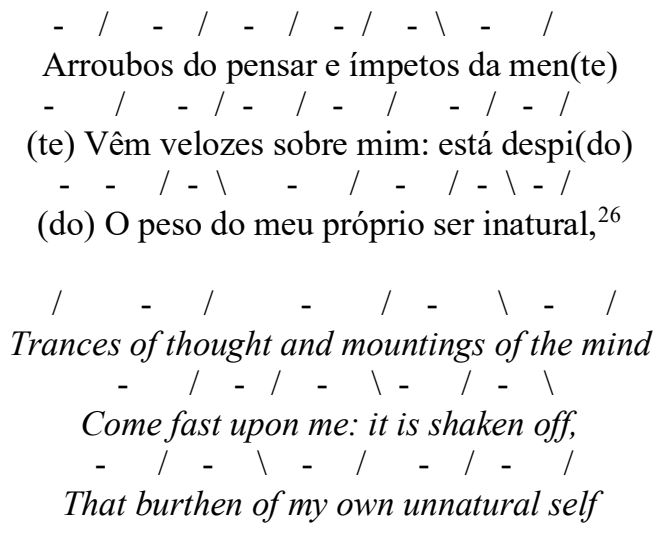

O ganho assim obtido pelo estabelecimento de uma subcorrente rítmica reconhecidamente iâmbica é significativo. Tradicionalmente, o decassílabo português, sendo puramente silábico, possui apenas o estrato do ritmo real, as restrições métricas operando apenas no sentido de eufonia. O pentâmetro iâmbico inglês, por outro lado, é acentual-silábico, e, portanto, constitui-se da tensão entre o ritmo real da linguagem e o ritmo potencial do metro, que modula o primeiro. O que a coexistência de dois ritmos independentes em um verso enseja é, de um lado, uma maior variabilidade acentual, visto que somente por força da expectativa acentual do metro pode ocorrer promoção e rebaixamento do acento silábico e o acento subtônico tornar-se relevante; por outro lado, uma diferente espécie de leitura é gerada, de prazer próprio, pois a cadência constante do ritmo métrico arrasta o leitor de forma inconsciente e sem esforço, ao mesmo tempo em que o ritmo da linguagem toma forma própria e variegada, por vezes mesmo atuando como contracorrente que se embate contra o metro, gerando efeitos expressivos.

Por fim, como exemplo aplicado de nossas considerações teóricas, apresentamos nossa própria tradução dos versos de abertura de The Prelude:

Quadro 3 - Comparação entre original de The Prelude e versão ao português de nossa autoria

\section{The Prelude (I, v. 1-30)}

[versão original]

O THERE is blessing in this gentle breeze,

$A$ visitant that while it fans my cheek

Doth seem half-conscious of the joy it brings

From the green fields, and from yon azure sky.

\section{O Prelúdio (I, v. 1-30)}

[versão nossa]

Ah, há uma benção nesta brisa delicada,

Um visitante que ao soprar em minha face

Até parece consciente do prazer

Que traz dos verdes campos e do céu azul. 


\begin{tabular}{|c|c|}
\hline Whate'er its mission, the soft breeze can come & Qualquer que seja o seu dever, a doce brisa \\
\hline To none more grateful than to me; escaped & Não virá a alguém mais grato do que eu; \\
\hline From the vast city, where I long had pined & Fugido da cidade, onde lamentei \\
\hline A discontented sojourner: now free, & Por tempo, um triste peregrino; agora livre, \\
\hline Free as a bird to settle where I will. & Livre como um pássaro pra achar meu lar. \\
\hline What dwelling shall receive me? in what vale & Que morada me receberá? Que vale \\
\hline Shall be my harbour? underneath what grove & Abarcará meu porto? Sob que arvoredo \\
\hline Shall I take up my home? and what clear stream & Habitarei? E qual regato cristalino \\
\hline Shall with its murmur lull me into rest? & Embalará com seu murmúrio meu repouso? \\
\hline The earth is all before me. With a heart & À minha frente está a terra. Com um coração \\
\hline Joyous, nor scared at its own liberty, & Alegre, sem temer a própria liberdade, \\
\hline I look about; and should the chosen guide & Eu olho à volta; e caso o guia eleito venha \\
\hline Be nothing better than a wandering cloud, & A ser não mais do que uma nuvem passageira, \\
\hline I cannot miss my way. I breathe again! & Não posso errar meu curso. Outra vez respiro! \\
\hline Trances of thought and mountings of the mind & Arroubos do pensar e ímpetos da mente \\
\hline Come fast upon me: it is shaken off, & Vem velozes sobre mim: está despido \\
\hline That burthen of my own unnatural self, & O peso do meu próprio ser inatural, \\
\hline The heavy weight of many a weary day & O fardo de incontáveis dias fatigantes \\
\hline Not mine, and such as were not made for me. & Que não meus, e tais que a mim não foram feitos. \\
\hline Long months of peace (if such bold word accord & Meses de profunda paz (se tal palavra audaz \\
\hline With any promises of human life), & Convém ao prometido pela vida humana), \\
\hline Long months of ease and undisturbed delight & Meses de profunda calma e de deleite \\
\hline Are mine in prospect; whither shall I turn, & Espero no porvir; para onde devo ir, \\
\hline By road or pathway, or through trackless field, & Por senda ou trilha, ou por campina inexplorada, \\
\hline Up hill or down, or shall some floating thing & Morro acima ou para baixo, ou há de algo \\
\hline Upon the river point me out my course? & A flutuar no rio mostrar o meu caminho? \\
\hline
\end{tabular}

Fonte: Wordsworth (1994).

\section{Conclusão}

O verso branco é uma forma poética ao mesmo tempo altamente estrita e maleável; obedece a um código métrico preciso, mas deve sua força às liberdades prosódicas do poeta que o emprega. Devido à sua condição liminar, entre prosa e poesia, adequado tanto à lírica quanto à épica e à meditação, o verso branco inglês possui um complexo de efeitos próprios que não são reproduzidos em outras formas. O ritmo iâmbico, junto ao uso de enjambement, extensos parágrafos poéticos e deslocamentos sintáticos gera no verso branco épico um singular efeito de corrente rítmica cumulativa, própria ao discurso sublime. Ao mesmo tempo, por outro lado, as variações métricas, como apontadas por David Jones, emprestam maior maleabilidade ao verso e o tornam propício para abarcar passagens de tom meditativo, descritivo, e até mesmo 
puramente prosaico. Percebemos, portanto, através das considerações levantadas pelos autores citados, que o verso branco é uma forma polivalente, capaz de abarcar, mesmo em sucessão, variações prosódicas e registros discursivos diversos sem que haja disrupção da forma padrão e da subcorrente rítmica.

O tradutor que desejar verter essa forma deve tomar em consideração tais efeitos e buscar meios de reproduzi-los na língua de chegada. Neste artigo, propomos uma forma métrica mista que, acreditamos, conserva aquelas qualidades tidas como fundamentais ao verso branco. Em nossa medida, adotamos também conforme a tradição inglesa, uma variabilidade de acentos métricos, admitindo sílabas átonas, tônicas e subtônicas, bem como promoção e rebaixamento de ênfase acentual, a fim de reproduzirmos de forma regular, mas não excessivamente marcada, a cadência binária do iambo inglês. Visando conservar o momento rítmico vertido de um verso a outro, característico da poesia inglesa, adotamos o procedimento incomum de contabilizar as sílabas excedentes de um verso grave como parte do verso sucedente, formando, juntamente com a sílaba tônica (ou subtônica) que abre o verso hendecassilábico seguinte, um iambo completo, de forma que a alternância rítmica não se rompe.

Após aplicarmos essa medida à tradução de passagens de The Prelude, pudemos perceber que a forma reproduz com sucesso aquelas qualidades objetivadas, particulares ao verso branco épico, sem as quais torna-se descaracterizado. Concluímos, portanto, que uma abordagem não convencional de padrões métricos e prosódicos pode beneficiar o ofício do tradutor de composições metrificadas, e que uma adaptação da forma visando a reprodução dos efeitos dessa, em vez de suas qualidades superficiais, através de um diálogo com a tradição métrica à qual a obra original é tributária, especialmente no que tange àqueles aspectos não contemplados pelas tradições métricas na língua de chegada, pode gerar resultados frutíferos e abrir novas perspectivas para os estudos tradutórios e possibilidades para o tradutor.

\section{REFERÊNCIAS}

ATTRIDGE, Derek. The rhythms of English poetry. London: Routledge, 1999.

JONES, David Keppel. The strict metrical tradition: variations in the literary iambic pentameter from Sidney and Spenser to Matthew Arnold. London: McGill-Queen's University Press, 2001.

MILTON, John. Paradise lost. Mineola: Dover Publications, 2005. 
MILTON, John. Paraíso Perdido. Traduzido por: António José de Lima Leitão. 1840. Disponível em: https://pt.wikisource.org/wiki/Para\%C3\%ADso_Perdido. Acesso em: 6 dez. 2019. Tradução de: Paradise Lost.

MILTON, John. Paraíso Perdido. Traduzido por: Daniel Jonas. São Paulo: Editora 34, 2015 Tradução de: Paradise Lost.

PEREIRA, Lawrence Flores. Nota sobre a tradução. In: SHAKESPEARE, William. A tragédia de Hamlet, príncipe da Dinamarca. Traduzido por: Lawrence Flores Pereira. São Paulo: Penguin Classics Companhia das Letras, 2015.

PEREIRA, Lawrence Flores. Nota sobre a tradução. In: SHAKESPEARE, William. A tragédia de Otelo, o mouro de Veneza. Traduzido por: Lawrence Flores Pereira. São Paulo: Penguin Classics Companhia das Letras, 2017.

SHAW, Robert. Blank verse: a guide to its history and use. Athens, Ohio: Ohio University Press, 2007.

SYMONDS, John Addington. Blank Verse. London: John C. Nimmo, 1895.

WEINFIELD, Henry. The blank verse tradition from Milton to Stevens: freethinking and the crisis of modernity. Cambridge: Cambridge University Press, 2012.

WORDSWORTH, William. O Prelúdio: ou o desenvolvimento do Espírito de um Poeta. Poema autobiográfico. Traduzido por: Maria de Lourdes Guimarães. Lisboa: Relógio D’Água, 2010. Tradução de: The Prelude.

WORDSWORTH, William. The prelude. In: WORDSWORTH, William. The collected poems of William Wordsworth. Ware: Wordsworth Edition, 1994.

\footnotetext{
* Angiuli Copetti de AGUIAR - Doutorando e Mestre em Letras (2017) pela Universidade Federal de Santa Maria. Graduado em Letras - Inglês e Literatura Inglesa (2013) pela mesma instituição. Santa Maria, Rio Grande do Sul, Brasil.

Currículo acadêmico: http://lattes.cnpq.br/3199611175115853

ORCID: https://orcid.org/0000-0003-4302-5067

E-mail: angiuli_c_a@hotmail.com

${ }^{1}$ Tradução nossa: "Eu olho à volta; e caso o guia eleito / Não seja mais do que uma nuvem passageira, / Não posso errar meu caminho. Eu respiro novamente".

2 Tradução nossa: "Ah, há uma bênção nesta brisa gentil".

${ }^{3}$ Tradução nossa: "Daquele leito macio não me ergui até que o sol".

4 "The five-beat line is characterised by its rhythmic variety, allowing the natural movement of speech to be imitated or heightened as the poet determines". (ATTRIDGE, 1999, p. 132)

5 "does not bring with it the sense of a strong underlying rhythm; it observes the heightened regularity of movement created by the alternation of stressed and unstressed syllables, without those rhythmic pulses grouping themselves consistently - and insistently - into twos and fours, and without any tendency for dipodic rhythms to make themselves felt. For this reason it strikes the ear as more faithful to the natural rhythm of speech: it is not that fivebeat groups are in any way indigenous to English, but that such groups impose themselves less strongly on the movement of the language. In other words, five-beat lines exhibit a different relationship between the two rhythmic principles that collaborate in the creation of metrical form: the rhythm of language speaks louder, the elementary rhythmic form more softly". (ATTRIDGE, 1999, p. 126)

6 "Even when it is organised by rhyme into stanza forms, the lines retain their separate identity as five-beat groups. This means that when we reach the end of the line there is no compelling pressure from the larger structure to
} 
register the completion of a rhythmic unit and to move on to the next one. Instead, the syntax has a more powerful voice - another example of the five-beat rhythm's less dominating relationship with the language - and will determine whether we pause or read straight on to the following line. Pentameter verse which consistently encourages us to pause at line-end will, of course, be marked by stronger rhythms, since the five-beat units will be highlighted; the liberal use of run-on lines, on the other hand, will create a continuous movement in which the line-divisions may not be very apparent". (ATTRIDGE, 1999, p. 133)

7 "ways in which the alternating stress-pattern of the syllables could be varied". (JONES, 2001, p. 4)

8 "At five points, namely on the even-numbered syllables, we not only recognize a stressed syllable as such but perceive it to have been duly preceded and introduced by an unstressed syllable. That moment of recognition coincides with the muscular impulse of enunciating the stressed syllable (aloud or as though aloud), which in turn gives rise to the sense of a beat. So the happy coincidence arises whereby the stressed syllable provides a focal point for a single act of rhythmic perception embracing two syllables. With each such act, even as the beat is registered, the account of that rhythmic unit with its two syllables is closed; and the account of the next unit is ready to proceed from a fresh start. With a fresh start, and with only two syllables to be accounted for, each step in this basic iambic process can be conducted almost unconsciously". (JONES, 2001, p. 35-36)

9 “Uma tempestade, uma energia redundante". (WORDSWORTH, 1994, I, v. 37, tradução nossa)

10 "Longos meses de paz (se tal palavra audaz concorda". (WORDSWORTH, 1994, I, v. 24, tradução nossa)

11 "Transes do pensar e elevações da mente". (WORDSWORTH, 1994, I, v. 19, tradução nossa)

12 "the most commonplace and the most sublime utterances". (SYMONDS, 1895, p. 16)

13 "though Blank Verse is an iambic rhythm, it owes its beauty to the liberties taken with the normal structure". (SYMONDS, 1895, p. 1)

14 "the accent required by the rhetorical significance of their abnormal lines". (SYMONDS, 1895, p. 2)

15 "being an accentual meter, blank verse owes much of its rhythmical quality to emphasis". (SYMONDS, 1895, p. 12)

16 "the true secret of blank verse consists in the proper adaptation of words and rhythms to the sense contained in them". (SYMONDS, 1895, p. 50-51)

17 "determined by the sense and intonation of the poet's thought". (SYMONDS, 1895, p. 64)

18 "the decasyllabic beat maintains an ininterrupted under-current of regular pulsations". (SYMONDS, 1895, p. 64)

19 "typically achieves its most memorable effects not in a single line but cumulatively". (SHAW, 2007, p. 26)

20 "commanding momentum, [a] sense of ongoingness, that is one of the leading characteristics (and advantages) of blank verse". (SHAW, 2007, p. 4)

21 "the sense variously drawn out from one verse into another". (MILTON, 2005, p. 1)

22 "Freedom and fixity are both at play in the form. Unchecked and unsegmented by patterns of rhyme, it can accommodate prodigious flows of utterance; in that sense it is freer. At the same time, unlike free verse, it has a set length of line and recurring number of beats, and while poets in practice may allow themselves flexible rhythms and even occasional metrical substitutions, these attain expressive power precisely because the standard iambic pentameter is there as a basis, a point to vary from". (SHAW, 2007, p. 4)

23 "first in Milton and then in the Romantic and modern poets who follow him in this mode, seems both to allow for and to promote what used to be called freethinking". (WEINFIELD, 2012, p. 2)

24 "Why think of any thing but present good?" (WORDSWORTH, 1994, I, v. 99).

25 "From that soft couch I rose not, till the sun" (WORDSWORTH, 1994, I, v. 86).

26 "Trances of thought and mountings of the mind / Come fast upon me: it is shaken off, / That burthen of my own unnatural self," (WORDSWORTH, 1994, I, v. 19-21). 